\title{
A select review reporting the quality of studies measuring endothelial dysfunction in randomised diet intervention trials
}

\author{
Rebecca B. Costello ${ }^{1 *}$, Cynthia V. Lentino ${ }^{1}$, Leila Saldanha ${ }^{1}$, Marguerite M. Engler ${ }^{2}$, Mary B. Engler ${ }^{2}$, \\ Pothur Srinivas ${ }^{3}$ and Christopher T. Sempos ${ }^{1}$ \\ ${ }^{1}$ Office of Dietary Supplements, National Institutes of Health, 6100 Executive Boulevard, Room 3B01, MSC 7517, \\ Bethesda, MD 20892-7517, USA \\ ${ }^{2}$ National Institute of Nursing Research, 31 Center Drive, Building 31, Room 5B10, Bethesda, MD 20892-2178, USA \\ ${ }^{3}$ The National Heart, Lung and Blood Institute, National Institutes of Health, Bethesda, MD 20892-7956, USA
}

(Submitted 6 January 2014 - Final revision received 20 June 2014 - Accepted 18 September 2014 - First published online 6 November 2014)

\section{Abstract}

A quality assessment of the primary studies reported in the literature carried out using select dietary ingredients (DI) purported to affect vascular endothelial function was conducted through a systematic PubMed search from January 2000 to August 2012. A total of seventy randomised controlled trials with defined DI (folic acid (fifteen), $n-3$ fatty acids (twenty), cocoa (fifteen) and isoflavones (twenty)) and standardised measures of vascular endothelial function were evaluated. Jadad scores, quality scoring parameters for DI and flow-mediated dilation (FMD) methodology used were ascertained. A total of 3959 randomised subjects, mean age 51 (sE 0.21) years (range 9-79 years), were represented in the dataset. The mean Jadad scores did not differ statistically among the DI studies, with the majority of the studies being of good quality. Higher DI quality scores were achieved by studies using the botanical ingredients cocoa and isoflavones than by those using the nutrient ingredients folic acid and $n-3$ fatty acids. The mean DI quality scores were $4 \cdot 13$ (SE $0 \cdot 34$ ), 5.20 (SE $0 \cdot 47$ ), 6.13 (SE $0 \cdot 41$ ) and 6.00 ( $\mathrm{se} 0.59$ ) for the folic acid, $n$-3 fatty acid, cocoa and isoflavone intervention studies, respectively (and significantly different). The mean Corretti FMD scores were 7.27 (sE 0.56), 7.46 (sE 0.79), 6.29 (sE 0.61) and 7.11 (sE 0.56) for the folic acid, $n$-3 fatty acid, cocoa and isoflavone intervention studies, respectively (NS). FMD studies failed to adequately describe the equipment used and more than half failed to provide an adequate description of the procedures used for vascular image acquisition and measurement. DI can be utilised for dietary intervention studies; however, the methodology should be clearly reported using the guidelines for assessment for both DI and FMD.

Key words: Dietary supplements: Dietary ingredients: Vascular function: Flow-mediated dilation: Systematic reviews

Emerging research suggests that dietary patterns can have a significant impact on vascular function and subsequent effects on health and disease ${ }^{(1)}$. Vascular endothelial function, most often measured non-invasively by assessing flow-mediated dilation (FMD), has been studied as a surrogate marker for atherosclerosis and an indicator of vascular health and reactivity ${ }^{(2)}$. It has been hypothesised that endothelial function may serve as an integrating index of risk factor burden and genetic susceptibility and that endothelial dysfunction will prove to be a preclinical marker for CVD. However, it remains to be determined whether an improvement in endothelial function directly translates into improved clinical outcomes.

A multitude of factors can affect endothelial function. These include a single energy-dense meal ${ }^{(3)}$, psychological stress $^{(4)}$, circulating concentrations of oestrogen and progesterone ${ }^{(5,6)}$, smoking ${ }^{(7-9)}$, acute changes in glucose concentrations ${ }^{(10,11)}$, shifts in electrolyte concentrations ${ }^{(12)}$ and pharmaceuticals ${ }^{(13)}$. A variety of dietary ingredients (DI) that are pharmacologically active are known to affect endothelial function including caffeine $^{(14)}$, flavanols found in cocoa ${ }^{(15-17)}$, tea ${ }^{(18,19)}$ and soya isoflavones $^{(20)}$. An array of DI have been clinically tested and reported to alter endothelial function. DI may alter endothelial function through multiple pathways such as by mediating the release of NO altering cell signalling pathways ${ }^{(21-24)}$, decreasing the production of pro-inflammatory cytokine concentrations $^{(25-27)}$, down-regulating the expression of cellular adhesion factors $^{(28-31)}$, and increasing or modulating the concentrations of antioxidant enzymes ${ }^{(32-34)}$ or indirectly by lowering the blood concentrations of homocysteine ${ }^{(35)}$.

Abbreviations: CONSORT, Consolidated Standards of Reporting Trials; DI, dietary ingredients; FMD, flow-mediated dilation; PICO, patient, intervention, comparator and outcome.

*Corresponding author: R. B. Costello, fax +11 301480 1845, email costellb@od.nih.gov 
Systematic reviews and meta-analyses are dependent on the validity and overall strength of the primary studies that are included in the review. It is equally important for researchers to provide an adequate description of the methodology employed in their studies to allow for reproducibility within the field. A number of standardised procedures have been developed to support a credible systematic review involving dietary constituents ${ }^{(36-38)}$. We utilised the patient, intervention, comparator and outcome (or PICO) method to formulate our research questions ${ }^{(39)}$.

Thus, the purpose of this review is to provide a quality assessment of the primary studies reported in the literature carried out using as interventions select DI purported to affect vascular endothelial function. These DI were folic acid, $n-3$ fatty acids, cocoa and isoflavones. Specifically, this review was designed to answer the following questions:

(1) How complete are the descriptions of DI interventions documented in randomised controlled trials measuring vascular function in targeted populations?

(2) Do the quality and completeness of reporting vary by the type of journal?

\section{Methods}

\section{Process of article selection}

The PICO questions guided the systematic search conducted using PubMed, EMBASE and the Cochrane Library collection from January 2000 to August 2012. Keywords in the search string included select vascular endothelium measures, vitamins, trace elements, fatty acids and botanicals (see online supplementary materials for the complete search string). Articles were included in the review if they reported studies carried out in healthy subjects, subjects with risk factors for CVD or clinically stable populations with chronic disease; studies with a randomised controlled trial design; studies in which the DI was consumed orally, in a defined supplement or ingredient form; and studies in which standard vascular assessment measures were reported. In addition, articles were limited to studies using DI that had been included in a published meta-analysis on endothelial dysfunction and considered a topic of public health importance. Studies were excluded if they were not randomised, the intervention was a whole or unrefined food, and the DI was used in combination with a drug therapy or another DI; if there was no dependent endothelial dysfunction measure; or if they were carried out in clinically unstable subjects. Studies reporting inflammatory markers without vascular measures were not included in this review. Abstracts were reviewed manually by two of the authors. Full-text articles were retrieved for manual review if inclusion by abstract was questionable. A total of fifty-two full-text articles were reviewed and excluded as they did not meet the inclusion criteria. Additional studies were also identified manually from published systematic reviews and meta-analyses on the same topic.

\section{Quality scoring parameters}

A variety of clinical trial quality tools appropriate for botanical and non-botanical DI intervention studies were employed. All studies were evaluated using the scoring tool of Jadad et al. ${ }^{(40)}$, designed to measure bias in clinical trial design (Table 1). For evaluating key methodological questions that should be addressed in DI intervention studies, guidelines for reporting micronutrient and botanical interventions ${ }^{(36,41)}$ were modified to arrive at quantitative scores. For determining a DI quality score, ten key methodological guidelines were selected to use as the basis for the scoring tool. These guidelines were derived either from the Consolidated Standards of Reporting Trials

Table 1. Jadad score for dietary ingredients: number of papers that responded to each of the questions

\begin{tabular}{|c|c|c|c|c|c|c|c|c|c|c|}
\hline \multirow[b]{3}{*}{ Reporting items for Jadad score } & \multicolumn{4}{|c|}{ Nutrients } & \multicolumn{4}{|c|}{ Botanicals } & \multirow{2}{*}{\multicolumn{2}{|c|}{$\begin{array}{l}\text { All the } \\
\text { seventy } \\
\text { articles }\end{array}$}} \\
\hline & \multicolumn{2}{|c|}{$\begin{array}{l}\text { Folic acid } \\
\qquad(n 15)\end{array}$} & \multicolumn{2}{|c|}{$\begin{array}{l}n-3 \text { Fatty } \\
\text { acids (n 20) }\end{array}$} & \multicolumn{2}{|c|}{ Cocoa $(n 15)$} & \multicolumn{2}{|c|}{$\begin{array}{l}\text { Isoflavones } \\
\quad(n 20)\end{array}$} & & \\
\hline & $n$ & $\%$ & $n$ & $\%$ & $n$ & $\%$ & $n$ & $\%$ & $n$ & $\%$ \\
\hline 1. Was the study described as randomised? & 15 & 100 & 20 & 100 & 15 & 100 & 20 & 100 & 70 & 100 \\
\hline $\begin{array}{l}\text { 2. Add one point: was the method used } \\
\text { to generate the sequence of } \\
\text { randomisation described and } \\
\text { was it appropriate? }\end{array}$ & 6 & $40 \cdot 0$ & 3 & $15 \cdot 0$ & 3 & $20 \cdot 0$ & 8 & $40 \cdot 0$ & 20 & $28 \cdot 6$ \\
\hline 3. Was the study described as double-blind? & 14 & $93 \cdot 0$ & 15 & $75 \cdot 0$ & 11 & $73 \cdot 3$ & 17 & $85 \cdot 0$ & 57 & 81.4 \\
\hline $\begin{array}{l}\text { 4. Add one point: was the method of } \\
\text { double-blinding described and was } \\
\text { it appropriate? }\end{array}$ & 10 & $66 \cdot 7$ & 14 & $70 \cdot 0$ & 10 & $66 \cdot 7$ & 12 & $60 \cdot 0$ & 46 & 65.7 \\
\hline $\begin{array}{l}\text { 5. Was there a description of withdrawals } \\
\text { and dropouts? }\end{array}$ & 9 & $60 \cdot 0$ & 16 & $80 \cdot 0$ & 11 & $73 \cdot 3$ & 17 & $85 \cdot 0$ & 53 & $75 \cdot 7$ \\
\hline $\begin{array}{l}\text { 6. Deduct one point: if the method used to } \\
\text { generate the sequence of randomisation } \\
\text { was described but was inappropriate }\end{array}$ & 1 & 6.7 & 0 & 0 & 0 & 0 & 0 & 0 & 1 & 1.4 \\
\hline $\begin{array}{l}\text { 7. Deduct one point: if the study was described } \\
\text { as double-blind, but the method of blinding } \\
\text { was inappropriate }\end{array}$ & 0 & 0 & 0 & 0 & 0 & 0 & 0 & 0 & 0 & 0 \\
\hline
\end{tabular}


Table 2. Dietary ingredient (DI) score: number of papers that responded to each of the questions

\begin{tabular}{|c|c|c|c|c|c|c|c|c|c|c|}
\hline \multirow[b]{3}{*}{ Reporting items for DI-related studies } & \multicolumn{4}{|c|}{ Nutrients } & \multicolumn{4}{|c|}{ Botanicals } & \multirow{2}{*}{\multicolumn{2}{|c|}{$\begin{array}{l}\text { All the } \\
\text { seventy } \\
\text { articles }\end{array}$}} \\
\hline & \multicolumn{2}{|c|}{$\begin{array}{l}\text { Folic acid } \\
\quad(n 15)\end{array}$} & \multicolumn{2}{|c|}{$\begin{array}{l}n \text {-3 Fatty } \\
\text { acids }(n 20)\end{array}$} & \multicolumn{2}{|c|}{ Cocoa $(n 15)$} & \multicolumn{2}{|c|}{$\begin{array}{l}\text { Isoflavones } \\
\quad(n 20)\end{array}$} & & \\
\hline & $n$ & $\%$ & $n$ & $\%$ & $n$ & $\%$ & $n$ & $\%$ & $n$ & $\%$ \\
\hline 1. Nutrient chemical form/IUPAC name & 15 & 100 & 20 & 100 & 11 & $73 \cdot 0$ & 13 & $65 \cdot 0$ & 59 & 84.3 \\
\hline 2. Chemical composition (formula) & 0 & 0 & 12 & $60 \cdot 0$ & 13 & $86 \cdot 7$ & 7 & $35 \cdot 0$ & 32 & $45 \cdot 7$ \\
\hline 3. Source of interventions & 6 & $40 \cdot 0$ & 16 & $80 \cdot 0$ & 15 & $100 \cdot 0$ & 17 & $85 \cdot 0$ & 54 & $77 \cdot 1$ \\
\hline 4. Validation of contents and testing methods & 0 & 0 & 1 & $5 \cdot 0$ & 5 & 33.3 & 8 & $40 \cdot 0$ & 14 & $20 \cdot 0$ \\
\hline 5. Dose of intervention & 6 & $40 \cdot 0$ & 11 & $55 \cdot 0$ & 13 & $86 \cdot 7$ & 5 & $25 \cdot 0$ & 45 & $64 \cdot 3$ \\
\hline 6. Baseline assessment of nutrient intake (diet) & 1 & $6 \cdot 6$ & 9 & $45 \cdot 0$ & 7 & $46 \cdot 7$ & 10 & $50 \cdot 0$ & 27 & $38 \cdot 6$ \\
\hline 7. Baseline assessment of nutrient status (biomarker) & 14 & $93 \cdot 3$ & 7 & $35 \cdot 0$ & 6 & $40 \cdot 0$ & 13 & $65 \cdot 0$ & 40 & $57 \cdot 1$ \\
\hline 8. Intervention nutrient assessment of nutrient intake (diet) & 1 & $6 \cdot 7$ & 8 & $40 \cdot 0$ & 6 & $40 \cdot 0$ & 8 & $40 \cdot 0$ & 23 & 32.9 \\
\hline $\begin{array}{l}\text { 9. Intervention nutrient assessment of nutrient } \\
\text { status (biomarker) }\end{array}$ & 14 & 93.3 & 7 & $35 \cdot 0$ & 6 & $40 \cdot 0$ & 14 & $70 \cdot 0$ & 41 & 58.6 \\
\hline 10. Attempts made to control for background diets & 5 & $33 \cdot 3$ & 9 & $45 \cdot 0$ & 10 & $66 \cdot 7$ & 15 & $75 \cdot 0$ & 43 & 61.4 \\
\hline
\end{tabular}

IUPAC, International Union of Pure and Applied Chemistry.

(CONSORT) herbal guidelines for botanicals ${ }^{(41)}$ or from the nutritional quality guidelines for the non-botanical $\mathrm{DI}^{(36)}$. A numerical score of ' 1 ' was assigned if the criterion was met and a score of ' 0 ' if the criterion was not met (Table 2). A quality score sheet or Corretti score ${ }^{(2)}$ was developed for reporting guidelines for intervention trials utilising the FMD ultrasound technique to measure endothelial function. Furthermore, twelve key methodological guidelines for the ultrasound assessment of the brachial artery proposed by Corretti were selected to use as the basis for the scoring tool (Table 3). A five-point placebo quality score was similarly developed based on the review criteria as reported by Golomb et al. ${ }^{(42)}$ (see online supplementary table). Journal types were tabulated using the National Library of Medicine designation for core clinical journals to assess whether reporting characteristics varied by journal categories and by description of study design and DI intervention. Journal types were sorted by core clinical, nutrition specialty, cardiovascular, not included in core clinical, and medical, not included in core clinical (see online supplementary table). Demographic and background data were extracted by two authors. Jadad, DI and placebo quality scoring was independently performed and scores were recorded by two authors in a blinded fashion. Corretti scores were independently recorded by three authors in a blinded fashion. Discrepancies in scoring were discussed and a consensus was reached.

\section{Statistical analyses}

The statistical analyses were performed using SAS 9.2 (SAS Institute, Inc.). Descriptive statistics, means and standard errors were obtained for all the continuous variables and percentages were obtained for all the categorical variables for the following seven groups: (1) folic acid; (2) n-3 fatty acids; (3) nutrient group (folic acid $+n$-3 fatty acids); (4) cocoa; (5) isoflavones; (6) botanical group (cocoa + isoflavones);

Table 3. Corretti flow-mediated dilation (FMD) score for dietary ingredients: number of papers that responded to each of the questions

\begin{tabular}{|c|c|c|c|c|c|c|c|c|c|c|}
\hline \multirow[b]{3}{*}{ Reporting items for FMD studies } & \multicolumn{4}{|c|}{ Nutrients } & \multicolumn{4}{|c|}{ Botanicals } & \multirow{2}{*}{\multicolumn{2}{|c|}{$\begin{array}{c}\text { All the } \\
\text { fifty-seven } \\
\text { FMD } \\
\text { articles }\end{array}$}} \\
\hline & \multicolumn{2}{|c|}{$\begin{array}{l}\text { Folic acid } \\
\quad(n 11)\end{array}$} & \multicolumn{2}{|c|}{$\begin{array}{l}n \text {-3 Fatty } \\
\text { acids }(n 13)\end{array}$} & \multicolumn{2}{|c|}{$\begin{array}{l}\text { Cocoa } \\
(n 14)\end{array}$} & \multicolumn{2}{|c|}{$\begin{array}{l}\text { Isoflavones } \\
\quad(n 19)\end{array}$} & & \\
\hline & $n$ & $\%$ & $n$ & $\%$ & $n$ & $\%$ & $n$ & $\%$ & $n$ & $\%$ \\
\hline Subject preparation (fasting) & 11 & 100 & 10 & $77 \cdot 0$ & 14 & 100 & 17 & 89.5 & 52 & $91 \cdot 2$ \\
\hline Subject preparation (vasoactive medications withheld) & 9 & 81.8 & 7 & 53.9 & 8 & $57 \cdot 1$ & 14 & 73.7 & 38 & $66 \cdot 7$ \\
\hline Room environment (temperature controlled, quiet) & 6 & 54.6 & 8 & 61.5 & 6 & 42.9 & 10 & $52 \cdot 6$ & 30 & $52 \cdot 6$ \\
\hline $\begin{array}{l}\text { Description of equipment: software 2D ultrasound } \\
\text { imaging colour and spectral Doppler with } \\
\text { internal ECG and high-frequency vascular transducer }\end{array}$ & 1 & $9 \cdot 1$ & 3 & $23 \cdot 1$ & 0 & 0 & 10 & $52 \cdot 6$ & 5 & $8 \cdot 7$ \\
\hline $\begin{array}{l}\text { Description of image acquisition and measurement; } \\
\text { specification of the longitudinal plane }\end{array}$ & 5 & $45 \cdot 5$ & 6 & $46 \cdot 1$ & 4 & $28 \cdot 6$ & 10 & $52 \cdot 6$ & 25 & $43 \cdot 9$ \\
\hline FDM measure - cuff placement (location) & 4 & $36 \cdot 4$ & 10 & $76 \cdot 9$ & 10 & 71.4 & 13 & 68.4 & 37 & 64.9 \\
\hline FMD measure - cuff inflation (time and duration) & 9 & $81 \cdot 8$ & 8 & 61.5 & 8 & $57 \cdot 1$ & 10 & $52 \cdot 6$ & 35 & 61.4 \\
\hline Timing of measurement - cuff release & 8 & $72 \cdot 7$ & 10 & $76 \cdot 9$ & 6 & $42 \cdot 9$ & 11 & 57.9 & 35 & 61.4 \\
\hline Timing of measurement -cardiac cycle & 5 & 45.4 & 8 & 61.5 & 5 & 35.7 & 11 & 57.9 & 29 & $50 \cdot 9$ \\
\hline Characterisation (definition) of FMD & 11 & 100 & 12 & $92 \cdot 3$ & 12 & $85 \cdot 7$ & 14 & 73.7 & 49 & $86 \cdot 0$ \\
\hline Method of evaluation of precision (blinding) & 5 & $45 \cdot 5$ & 6 & $46 \cdot 1$ & 7 & $50 \cdot 0$ & 9 & $47 \cdot 4$ & 27 & $47 \cdot 4$ \\
\hline $\begin{array}{l}\text { Sample size (cross-over: twenty to thirty, } \\
\text { parallel: forty to sixty) }\end{array}$ & 6 & $54 \cdot 6$ & 9 & $69 \cdot 2$ & 8 & $57 \cdot 1$ & 15 & 78.9 & 38 & $66 \cdot 7$ \\
\hline
\end{tabular}

2D, two-dimensional; ECG, electrocardiography. 
(7) nutrient group and botanical group combined. Significance was set at $P<0.05$. The SAS general linear model procedure (PROC GLM; SAS Institute, Inc.) was used to conduct ANOVA. Regression analysis was used to compare the folic acid, $n-3$ fatty acid, cocoa and isoflavone intervention studies, with the folic acid intervention studies being used as the reference group. Outcome data (FMD measures) from individual studies were not pooled for the statistical analyses.

\section{Results}

\section{Search results}

Four DI that had been the subject of meta-analyses were evaluated: folic acid, $n-3$ fatty acids, cocoa and isoflavones. These DI met the inclusion criteria (Fig. 1). The DI that were excluded because they did not meet the inclusion criteria included antioxidants, B vitamins, amino acids, vitamin C, vitamin $\mathrm{E}$, $\alpha$-lipoic acid and those using combination ingredients. This resulted in a dataset of seventy randomised controlled trials: fifteen folic acid ${ }^{(43-57)}$; twenty $n$-3 fatty acids ${ }^{(58-77)}$; fifteen cocoa $^{(78-92)}$; twenty isoflavones ${ }^{(93-112)}$. These articles provided a description of DI and standardised vascular-dependent measures of endothelial function (see online supplementary materials for the complete data design tables).

\section{Description of the dataset}

A total of 3959 randomised subjects, mean age 51 (SE 0.21) years (range 9-79 years), were represented in the dataset. Of the studies included, $66 \%$ had healthy subjects enrolled, with the majority including both men and women. Approximately one-third (36\%) of the subjects continued using concomitant medications during the study period. Cross-over design studies accounted for $47 \%$ of those included in the dataset. The most common measure used to evaluate vascular endothelial function was FMD at 81.4\%; other measures (e.g. pulse wave velocity, forearm arterial blood flow, augmentation index, ankle-brachial pressure index, cardio-ankle vascular index, fingertip pulse wave amplitude and hyperaemic response) were seldom used in the studies (Table 4).

\section{Quality scoring parameters}

The overall mean Jadad score was $3 \cdot 50$ (se 0.13) (maximum score of 5). The mean Jadad scores were 3.53 ( $\operatorname{se~0.21),~} 3.40$ ( $\operatorname{se} 0 \cdot 25$ ), 3.30 (se 0.36 ) and 3.70 (se 0.20 ) for the folic acid, $n-3$ fatty acid, cocoa and isoflavone intervention studies, respectively, and did not differ statistically among the supplement studies (Table 1). Studies achieving a Jadad score $\geq 3$ were considered to be free of bias and therefore of higher quality. A Jadad score of 5 was achieved by nine studies.

The overall mean DI score was $5 \cdot 40$ (SE 0.25) out of 10. Studies carried out on the four DI evaluated in this review achieved an individual DI quality reporting score. The mean DI quality scores were $4 \cdot 13$ (SE 0.34), 5.20 (SE 0.47), 6.13 (SE 0.41) and 6.00 (se 0.59 ) for the folic acid, $n-3$ fatty acid, cocoa and isoflavone intervention studies, respectively (Table 2 and Fig. 2). Of the articles reviewed, $73 \%$ had included the DI source or supplier, $64 \%$ included the intervention dosage and study duration, 57\% included the baseline nutrient biomarker assessment, and only $39 \%$ included the baseline nutrient assessment. A statistically

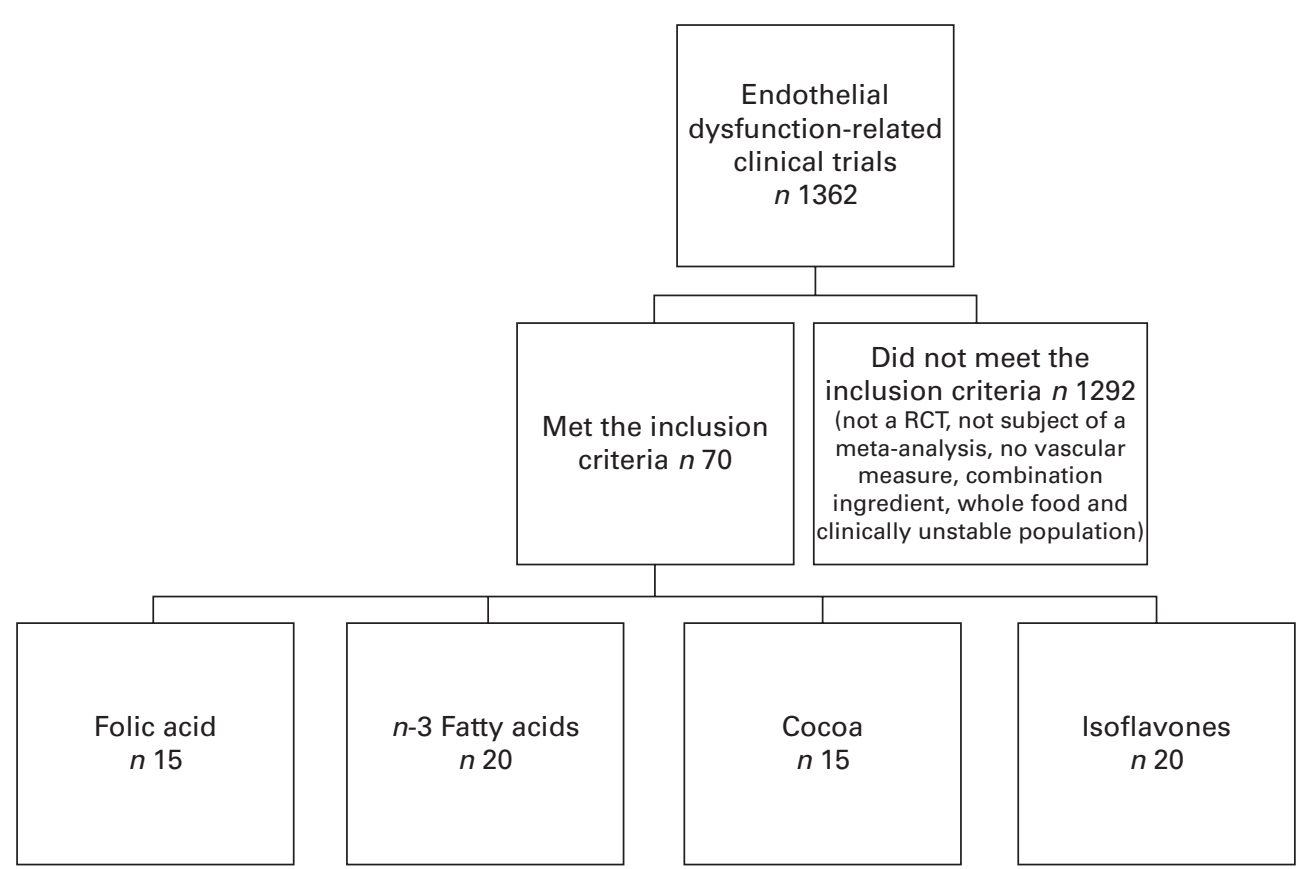

Fig. 1. Results of the PubMed search strategy with the resulting seventy studies included in the review. Studies were excluded if the dietary ingredients (DI) evaluated had not been the subject of a meta-analysis and were not randomised, the intervention was a whole or unrefined food, and the DI was used in combination with a drug therapy or another $\mathrm{DI}$; if there was no dependent endothelial dysfunction measure; or if the study sample comprised clinically unstable subjects. RCT, randomised controlled trials. 
Table 4. Vascular-dependent measures of endothelial function

\begin{tabular}{lrr}
\hline Vascular measures & $n$ & $\%^{*}$ \\
\hline Flow-mediated dilation & 57 & $81 \cdot 4$ \\
Pulse wave velocity & 9 & $12 \cdot 8$ \\
Forearm arterial blood flow & 7 & $10 \cdot 0$ \\
Augmentation index & 4 & $5 \cdot 7$ \\
Ankle-brachial pressure index & 1 & $1 \cdot 4$ \\
Cardio-ankle vascular index & 1 & $1 \cdot 4$ \\
Brachial artery blood flow and diameter & 1 & $1 \cdot 4$ \\
Fingertip pulse wave amplitude & 3 & $4 \cdot 3$ \\
Hyperaemic response & 3 & $4 \cdot 3$ \\
$\quad$ (includes ionophoresis vascular reactivity) & & \\
\hline
\end{tabular}

* Will not add to $100 \%$, as several studies used multiple measures.

significant higher DI quality score was achieved by botanical supplement studies than by nutrient supplement studies $(P=0 \cdot 01)$. Only thirteen studies achieved a DI quality score $\geq 8$ and one study achieved a score of 10 .

Studies utilising folic acid as the intervention most consistently used $5 \mathrm{mg} / \mathrm{d}$ (range $400 \mu \mathrm{g}-1600 \mathrm{mg}$ ); one study used folic acid in the form of 5-methyltetrahydrofolate. None of the articles reporting folic acid intervention studies provided the specific chemical formula for the DI used (e.g. sodium folate or calcium folate). Placebo or comparator ingredients were poorly characterised. The duration of studies ranged from 1 to 52 weeks, and blood folic acid concentrations were determined before or after the intervention period in nine of the fifteen studies.

The $n$ - 3 fatty acid intervention studies included trials utilising fish-oil mixtures containing both DHA and EPA, capsules containing DHA alone, or capsules containing EPA alone. Of the articles reporting $n$-3 fatty acid intervention studies, $60 \%$ provided the specific chemical form for the DI used (e.g. ester or TAG). The doses of fish-oil mixtures ranged from 1.0 to $4.0 \mathrm{~g} / \mathrm{d}$; DHA from $290 \mathrm{mg}$ to $1.5 \mathrm{~g} / \mathrm{d}$, and EPA from 300 to $1800 \mathrm{mg} / \mathrm{d}$. The duration of studies ranged from 2 to 152 weeks. Olive oil was the predominant comparator oil utilised.

A wide range of interventions containing cocoa (Theobroma cacao) flavanols were utilised including beverages, bars and powder. The chemical composition of the DI was clearly defined in $87 \%$ of the articles. The doses of flavanols ranged from 88 to $963 \mathrm{mg} / \mathrm{d}$ and studies lasted from $2 \mathrm{~d}$ to 12 weeks. Acute sampling or sampling at multiple time points within $1 \mathrm{~d}$ of study was performed in five trials included the dataset. The comparators used in the cocoa intervention studies were typically low-flavonoid preparations.

Unlike in the cocoa intervention studies, the chemical compositions of the DI used in the soya isoflavone (Glycine max) intervention studies were poorly described. Intervention DI included a range of isoflavones as purified capsules, powder, spread, tablets and fortified soya germ pasta. Comparator formulations were varied and included matching placebo, components not specified, caseinate protein powder, milk protein powder, cereal bars or conventional pasta. Doses ranged from 33 to $200 \mathrm{mg} / \mathrm{d}$ and studies lasted from 2 to 56 weeks. Only four $(20 \%)$ of the studies provided information on the amounts of the glycoside form (as genistin, daidzin or glycitin) as well as the aglycone form (as genistein, daidzein or glycitein) of the isoflavone present in the intervention.

A positive vascular outcome was reported as determined by the study investigators. FMD, assessed by brachial artery ultrasound, was used as the primary outcome measure in fifty-seven ( $81 \%$ ) of the seventy trials. A positive FMD outcome was reported in $61 \%$ of the articles $(93 \%$ for cocoa, $62 \%$ for $n$ 3-fatty acids, $48 \%$ for isoflavones and $46 \%$ for folic acid). Differences were found between cocoa and folic acid intervention studies $(P=0.02)$ and cocoa and isoflavone intervention studies $(P=0 \cdot 02)$ (Fig. 3). The overall mean Corretti score for the fifty-seven studies utilising the FMD methodology was 7.01 (SE 0.32 ) out of 12 . The mean Corretti scores were 7.27 (SE 0.56), 7.46 (SE 0.79), 6.29 (sE 0.61 ) and $7 \cdot 11$ (SE 0.56) for the folic acid, $n-3$ fatty acid, cocoa and isoflavone intervention studies, respectively. The nutrient DI (folic acid and $n$-3 fatty acid) studies had slightly higher Corretti scores (7.34 (SE 0.49)) than the botanical DI (cocoa and isoflavone) studies (6.76 (sE 0.41)). There were no statistically significant differences among the supplement studies (Table 3). Over $90 \%$ of the studies failed to adequately describe the equipment used to measure FMD and more than half of the studies failed to provide an adequate description of the procedures used for vascular image acquisition and measurement. Lastly, one-third of the studies did not have adequate sample size for determination of the primary outcome measure of FMD by the Corretti guidelines.

Overall, placebo controls and/or comparators were poorly described; only $41 \%$ of the included articles had detailed descriptions of the placebo treatment and only $31 \%$ of the articles had adequate descriptions of all its constituents. The rationale for the type of control or placebo used was also lacking, as well as its physical appearance and likeness to the intervention under study (see online supplementary materials for the placebo scoring sheet).

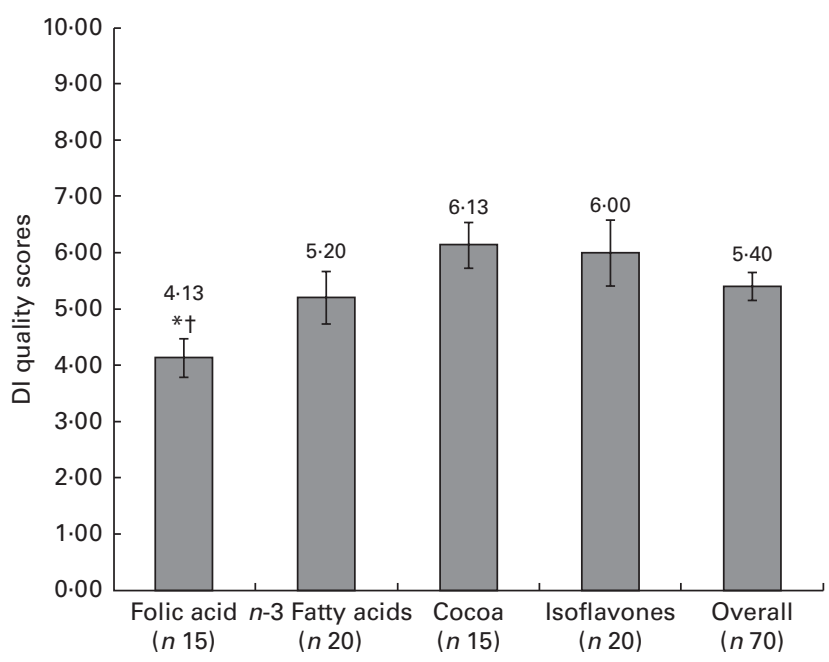

Fig. 2. Mean dietary ingredient (DI) quality scores for the folic acid, $n-3$ fatty acid, cocoa and isoflavone intervention studies. ${ }^{*} \mathrm{DI}$ score was significantly different from that of the cocoa intervention studies $(P=0.04)$. $\dagger \mathrm{DI}$ score was significantly different from that of the isoflavone intervention studies $(P=0.03)$. 


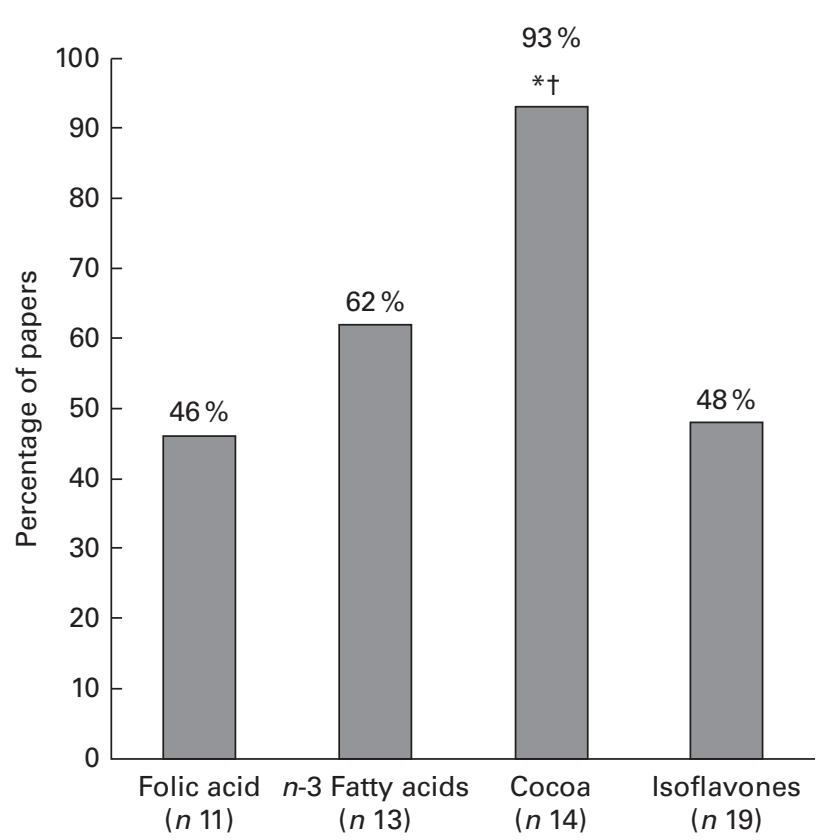

Fig. 3. Percentage of articles reporting a positive flow-mediated dilation outcome as determined by the investigator. * Score was significantly different from that of the folic acid intervention studies $(P=0.02)$. † Score was significantly different from that of the isoflavone intervention studies $(P=0.02)$.

\section{Journal characteristics}

Journal types were sorted by core clinical (29\%), nutrition related $(20 \%)$, other cardiovascular $(29 \%)$ that were not included in core clinical and other medical (23\%) that were also not included in core clinical. Core clinical journal type was defined using the National Library of Medicine definition $^{(113)}$. The distribution of DI articles across the journal categories was somewhat uniform (see online supplementary materials for journal listing). No association was evident between journal type and Jadad or Corretti score, but a significant association was evident between journal type and DI quality score. The DI quality score for studies reported in core clinical journals was 5.30 (SE 0.77). Studies reported in nutrition-related journals achieved the highest DI quality score (mean 7.00 (SE 0.84)), and the scores of studies reported in these journals were significantly different from those of studies reported in other cardiovascular journals (mean 4.85 (SE 0.57); $P=0.02$ ) and other medical journals (mean 4.81 (SE 0.56$) ; P=0.02$ ). Of the thirty-five journals, eleven (28\%) included endorsement of the CONSORT guidelines.

\section{Subgroup analyses}

Subgroup analyses by clinical trial design features revealed non-cross-over FMD studies, independent of the DI, to have significantly higher Jadad scores than cross-over studies $(3.76$ ( $\operatorname{se} 0 \cdot 14) v \cdot 3 \cdot 21(\operatorname{se} 0 \cdot 20) ; P=0 \cdot 03)$. The analysis of trial design by DI quality score or Corretti score revealed no differences between non-cross-over and cross-over studies. No association was evident between the population group (primary $v$. secondary) and the Jadad, DI quality or Corretti score.

\section{Discussion}

The DI selected in this quality review have been shown to alter endothelial function and have been studied extensively as well as included in meta-analyses. To our knowledge, this is the first review to evaluate the quality reporting of a select group of DI interventions and corresponding comparators for endothelial dysfunction. In addition, a scoring system was developed to evaluate the reporting of the methodology used to assess FMD and endothelial function, which is not typically done in systematic reviews and meta-analyses. Other reviews and meta-analyses have addressed issues of bias, doseresponse effects and sensitivity analysis in concert with a pooled meta-analysis of the data on $\operatorname{cocoa}^{(114,115)}, n-3$ fatty $\operatorname{acids}^{(116,117)}$, soya isoflavones ${ }^{(118)}$ and folic acid ${ }^{(119,120)}$, and most of them have concluded that supplementation improved the parameters of endothelial function. We have shown that the peer-reviewed literature is significantly deficient in providing an adequate description of the background and intervention diets as evaluated previously in a critical appraisal of the reporting of systematic reviews of micronutrients and health ${ }^{(36)}$. Although the use of quality measures or scoring tools does not necessarily correlate with improved outcomes or the strength of treatment effects across studies, these measures may be appropriate in specific well-defined areas of study and offer some benefits ${ }^{(11,37,121,122)}$.

Nutrient-specific guidance has been proposed for designing, implementing and reporting clinical studies specifically for soya interventions. It is recommended that the investigator know and report the product source and supplies; analyse, describe and report all the potential bioactive constituents relevant to the study; conduct independent analyses of test and placebo agents; express isoflavone values as aglycone equivalents or present isoflavone values with sufficient information so that they can be readily converted to aglycone equivalents for cross-study comparisons; and refer to the CONSORT guidelines for reporting herbal interventions ${ }^{(123)}$. Similar information for other DI intervention studies is essential to improve the accuracy and enhance the quality of the studies.

The Jadad scores were comparable across the DI studies, with the majority of the studies being of good quality. Higher DI quality scores were achieved by studies using the botanical ingredients cocoa and isoflavones than by those using the nutrient ingredients folic acid and $n$ - 3 fatty acids. For cocoa, this may be reflected by repeated use of the same highly characterised product under study. DI quality scores, particularly for folic acid interventions, were significantly affected by the lack of validation of the test materials and lack of documentation of the baseline diet. Many of these studies used pharmacological doses of folic acid for indications of lowering plasma homocysteine concentrations. As expected, the descriptions of DI interventions were more complete in studies reported in nutrition journals. Given the small numbers of studies conducted for each DI, comparison across individual journals was not possible.

Although systematic reviews are prevalent in the literature, there are unique challenges to applying this approach to the field of nutrition science. Nutrition-related considerations 
include baseline nutrient exposure, nutrient status, bioequivalence of bioactive compounds, bioavailability, multiple and interrelated biological functions, undefined nature of some interventions and uncertainties in dietary intake assessment. In addition, the methodological quality of the primary literature upon which the systematic reviews are based is often poor or inadequately reported, as the individual studies often do not report information that is critical to interpret their findings or to replicate the study. Standards are needed to improve the conduct and reporting of systematic reviews in the field of nutrition science. The quality of clinical trial design can be evaluated and reported in the peerreviewed literature using various reporting tools. Quality reporting tools for trial design, Jadad scores, and characterisation of botanical and nutrient test materials were used in this review. A nutrient quality score was derived from the proposed Agency for Healthcare Research and Quality guidelines as reported by Chung et $a l .^{(36)}$. The 2006 revised CONSORT statement ${ }^{(41)}$ guides reporting of randomised control trials of herbal medicine interventions to include the product name, characteristics of herbal product, and qualitative and quantitative testing of the products. Several of these key features were incorporated into the nutrient scoring tool. We relied heavily on the procedure guidelines proposed by Corretti et $a l .{ }^{(2)}$ for evaluating the quality of studies utilising ultrasound measures of FMD, as they were available to most researchers encompassed in this literature review.

Brachial artery FMD provides a non-invasive measure of endothelial function and specific guidelines have been developed to ensure the accuracy and quality of the measurement. The key methodological characteristics of the assessment of endothelial function that were reported in DI intervention studies were documented in this systematic review. The details of the methodology used to assess the outcome measure of FMD were also scarce in the studies reviewed. The procedures used for the measurement of FMD were not uniformly reported in standardised formats or according to the recommended guidelines ${ }^{(2)}$, which adds potential variability and confounding to the measurement of endothelial function. Interestingly, there was under-reporting of specific anatomical imaging sites, CV for test reproducibility and blinding of study personnel to image analysis in the studies. General recommendations from the guidelines for ultrasound assessment of the brachial artery include twenty to thirty subjects for cross-over studies and forty to sixty subjects for parallel-group design studies ${ }^{(2)}$. FMD assessment has become a standard tool and non-invasive method to measure endothelial function ${ }^{(7)}$. FMD correlates with endothelial function of the coronary $\operatorname{arteries}^{(124)}$. Brachial artery FMD is reportedly an independent predictor of cardiovascular events ${ }^{(125-127)}$. However, this has not been demonstrated in other studies ${ }^{(128,129)}$. The controversy may be due to the accuracy and variability in the measurement of brachial artery FMD. Factors including expertise of the sonographer, type of ultrasound equipment and technology used, subject preparation, vascular occlusion location, environmental conditions in the room where measurements are taken and method of analyses can influence the measurement of brachial artery FMD. These limitations are revealed by dietary intervention studies measuring brachial artery FMD included in this review.

Guidelines for the ultrasound assessment of brachial artery FMD have been developed ${ }^{(2,130,131)}$. With the advancement of ultrasound technology and widespread clinical applications for testing, these guidelines and recommendations will assist clinicians and researchers in the accurate measurement of endothelial function. This methodology can help track individuals on dietary interventions that have the potential to decrease the risk of CVD. It is broadly applicable to patients because it is non-invasive, stable and reliable ${ }^{(132)}$. Ultrasound assessment of brachial artery FMD is also ideal in dietary studies with serial measurements and short-term or longterm durations. However, future studies using this technique need to be standardised using the guidelines for assessment to increase accuracy and minimise all the potential variables.

\section{Limitations of the review}

The focus of this review was on the reporting quality of DI purported to affect vascular endothelial function in clinical trials reported in the peer-reviewed literature. Therefore, the degree of reporting bias was not assessed. We were interested in determining whether DI intervention studies included in meta-analyses assessing FMD were adequately and appropriately characterised. We made an attempt to correlate DI quality scores with FMD outcomes. Unfortunately, it was not possible to include a more robust measure of FMD outcome, such as percentage change in FMD, as not all articles uniformly reported FMD outcomes in a similar manner or in similar units. Therefore, the outcome of a 'positive' or 'negative' FMD study based on the investigator's assessment should be treated with caution. The quality scoring tools used for the determination of a nutrient score, a Corretti score and a placebo score are presented as guidelines for the inclusion of pertinent information for DI intervention studies evaluating FMD; these tools have not been validated yet.

\section{Conclusions}

The purpose of this quality review was to highlight the need for accurate and complete reporting by clinical researchers so that their work can be communicated succinctly and replicated by others. The descriptive and statistical treatment of the data suggests weaknesses in the study design and conduct of the study, based on what was reported in the articles. The clinical relevance of this systematic review is that the DI reviewed had favourable effects on endothelial dysfunction as determined by the investigator's assessment of a positive or negative study. Lastly, guideline papers are available for reference to assist investigators in designing DI intervention studies with greater methodological controls and enhanced reporting in peer-reviewed journals.

\section{Supplementary material}

To view supplementary material for this article, please visit http://dx.doi.org/10.1017/S0007114514003353 


\section{Acknowledgements}

The authors thank Joyce Merkel for her technical and editorial contributions and Susan Pilch for conducting the literature searches.

The Office of Dietary Supplements, National Institutes of Health, funded and sponsored this work.

The authors' contributions are as follows: R. B. C. designed the analysis and performed data extraction and grading of quality scores; C. V. L. contributed to data collection and analysis; L. S., M. B. E. and M. M. E. performed data extraction and grading of quality scores; P. S. contributed to data extraction; C. T. S. performed the statistical analyses. All authors contributed to the drafting of the article and read, reviewed and approved the final manuscript.

The authors report no conflicts of interest. The opinions or assertions reported herein are the those of the author(s) and are not to be construed as official or reflecting the views of the National Institutes of Health, the National Heart, Lung, and Blood Institute, the National Institute of Nursing Research, or the Office of Dietary Supplements.

\section{References}

1. Vanhoutte PM (2009) Endothelial dysfunction: the first step toward coronary arteriosclerosis. Circ J 73, 595-601.

2. Corretti MC, Anderson TJ, Benjamin EJ, et al. (2002) Guidelines for the ultrasound assessment of endothelialdependent flow-mediated vasodilation of the brachial artery. J Am Coll Cardiol 39, 257-265.

3. Vogel RA, Corretti MC \& Plotnick GD (1997) Effect of a single high-fat meal on endothelial function in healthy subjects. Am J Cardiol 79, 350-354.

4. Gu HF, Tang CK \& Yang YZ (2012) Psychological stress, immune response, and atherosclerosis. Atherosclerosis 223, 69-77.

5. Knowlton AA \& Lee AR (2012) Estrogen and the cardiovascular system. Pharmacol Ther 135, 54-70.

6. Simoncini T (2009) Mechanisms of action of estrogen receptors in vascular cells: relevance for menopause and aging. Climacteric 12, Suppl. 1, 6-11.

7. Celermajer DS, Sorensen KE, Bull C, et al. (1994) Endothelium-dependent dilation in the systemic arteries of asymptomatic subjects relates to coronary risk factors and their interaction. J Am Coll Cardiol 24, 1468-1474.

8. Csordas A \& Bernhard D (2013) The biology behind the atherothrombotic effects of cigarette smoke. Nat Rev Cardiol 10, 219-230.

9. Messner B \& Bernhard D (2014) Smoking and cardiovascular disease: mechanisms of endothelial dysfunction and early atherogenesis. Arterioscler Thromb Vasc Biol 34, 509-515.

10. Ceriello A, Quagliaro L, Piconi L, et al. (2004) Effect of postprandial hypertriglyceridemia and hyperglycemia on circulating adhesion molecules and oxidative stress generation and the possible role of simvastatin treatment. Diabetes 53, 701-710.

11. O'Keefe JH, Gheewala NM \& O'Keefe JO (2008) Dietary strategies for improving post-prandial glucose, lipids, inflammation, and cardiovascular health. J Am Coll Cardiol 51, 249-255.

12. Liu Z, Peng J, Lu F, et al. (2013) Salt loading and potassium supplementation: effects on ambulatory arterial stiffness index and endothelin-1 levels in normotensive and mild hypertensive patients. J Clin Hypertens (Greenwich) $\mathbf{1 5}$, 485-496.

13. Bryan NS (2012) Pharmacological therapies, lifestyle choices and nitric oxide deficiency: a perfect storm. Pharmacol Res 66, 448-456.

14. Shechter M, Shalmon G, Scheinowitz M, et al. (2011) Impact of acute caffeine ingestion on endothelial function in subjects with and without coronary artery disease. $\mathrm{Am} \mathrm{J}$ Cardiol 107, 1255-1261.

15. Heiss C, Finis D, Kleinbongard P, et al. (2007) Sustained increase in flow-mediated dilation after daily intake of high-flavanol cocoa drink over 1 week. $J$ Cardiovasc Pharmacol 49, 74-80.

16. Ottaviani JI, Momma TY, Heiss C, et al. (2011) The stereochemical configuration of flavanols influences the level and metabolism of flavanols in humans and their biological activity in vivo. Free Radic Biol Med 50, 237-244.

17. Grassi D, Mulder TP, Draijer R, et al. (2009) Black tea consumption dose-dependently improves flow-mediated dilation in healthy males. $J$ Hypertens 27, 774-781.

18. Duffy SJ, Keaney JF Jr, Holbrook M, et al. (2001) Short- and long-term black tea consumption reverses endothelial dysfunction in patients with coronary artery disease. Circulation 104, 151-156.

19. Vita JA (2003) Tea consumption and cardiovascular disease: effects on endothelial function. J Nutr 133, 3293S-3297S.

20. Teragawa H, Higashi Y \& Kihara Y (2008) Effect of isoflavone supplement on endothelial function: does efficacy vary with atherosclerotic burden? Eur Heart $J$ 29, 2710-2712.

21. Steffen Y, Jung T, Klotz LO, et al. (2007) Protein modification elicited by oxidized low-density lipoprotein (LDL) in endothelial cells: protection by $(-)$-epicatechin. Free Radic Biol Med 42, 955-970.

22. Schini-Kerth VB, Etienne-Selloum N, Chataigneau T, et al. (2011) Vascular protection by natural product-derived polyphenols: in vitro and in vivo evidence. Planta Med $\mathbf{7 7}$, 1161-1167.

23. Selmi C, Mao TK, Keen CL, et al. (2006) The anti-inflammatory properties of cocoa flavanols. (discussion S172-S176). J Cardiovasc Pharmacol 47, Suppl. 2, S163-S171.

24. Shapiro H, Lev S, Cohen J, et al. (2009) Polyphenols in the prevention and treatment of sepsis syndromes: rationale and pre-clinical evidence. Nutrition 25, 981-997.

25. Spector AA, Kaduce TL, Figard PH, et al. (1983) Eicosapentaenoic acid and prostacyclin production by cultured human endothelial cells. J Lipid Res 24, 1595-1604.

26. von Schacky C (2007) n-3 PUFA in CVD: influence of cytokine polymorphism. Proc Nutr Soc 66, 166-170.

27. Massaro M, Habib A, Lubrano L, et al. (2006) The omega-3 fatty acid docosahexaenoate attenuates endothelial cyclooxygenase-2 induction through both $\mathrm{NADP}(\mathrm{H})$ oxidase and PKC epsilon inhibition. Proc Natl Acad Sci U S A 103, 15184-15189.

28. Saravanan P, Davidson NC, Schmidt EB, et al. (2010) Cardiovascular effects of marine omega-3 fatty acids. Lancet 376, 540-550.

29. de Roos B, Mavrommatis Y \& Brouwer IA (2009) Longchain $n-3$ polyunsaturated fatty acids: new insights into mechanisms relating to inflammation and coronary heart disease. Br J Pharmacol 158, 413-428.

30. De Caterina R \& Massaro M (2005) Omega-3 fatty acids and the regulation of expression of endothelial pro-atherogenic and pro-inflammatory genes. J Membr Biol 206, 103-116. 
31. De Caterina R, Madonna R \& Massaro M (2004) Effects of omega-3 fatty acids on cytokines and adhesion molecules. Curr Atheroscler Rep 6, 485-491.

32. Guo Q, Rimbach G, Moini H, et al. (2002) ESR and cell culture studies on free radical-scavenging and antioxidant activities of isoflavonoids. Toxicology 179, 171-180.

33. Schewe T, Steffen Y \& Sies H (2008) How do dietary flavanols improve vascular function? A position paper. Arch Biochem Biophys 476, 102-106.

34. Forstermann U \& Munzel T (2006) Endothelial nitric oxide synthase in vascular disease: from marvel to menace. Circulation 113, 1708-1714.

35. Wald DS, Wald NJ, Morris JK, et al. (2006) Folic acid, homocysteine, and cardiovascular disease: judging causality in the face of inconclusive trial evidence. BMJ 333, 1114-1117.

36. Chung M, Balk EM, Ip S, et al. (2009) Reporting of systematic reviews of micronutrients and health: a critical appraisal. Am J Clin Nutr 89, 1099-1113.

37. Moher D, Cook DJ, Eastwood S, et al. (1999) Improving the quality of reports of meta-analyses of randomised controlled trials: the QUOROM statement. Lancet 354, $1896-1900$

38. Stroup DF, Berlin JA, Morton SC, et al. (2000) Meta-analysis of observational studies in epidemiology. A proposal for reporting. JAMA 283, 2008-2012.

39. Lichtenstein AH, Yetley EA \& Lau J (2008) Application of systematic review methodology to the field of nutrition. J Nutr 138, 2297-2306.

40. Jadad AR, Moore A, Carroll D, et al. (1996) Assessing the quality of reports of randomized clinical trials: is blinding necessary? Control Clin Trials 17, 1-12.

41. Gagnier JJ, Boon H, Rochon P, et al. (2006) Reporting randomized, controlled trials of herbal interventions: an elaborated CONSORT statement. Ann Intern Med 144, 364-367.

42. Golomb BA, Erickson LC, Koperski S, et al. (2010) What's in placebos: who knows? Analysis of randomized, controlled trials. Ann Intern Med 153, 532-535.

43. Doshi SN, McDowell IF, Moat SJ, et al. (2002) Folic acid improves endothelial function in coronary artery disease via mechanisms largely independent of homocysteine lowering. Circulation 105, 22-26.

44. Doshi SN, McDowell IF, Moat SJ, et al. (2001) Folate improves endothelial function in coronary artery disease: an effect mediated by reduction of intracellular superoxide? Arterioscler Thromb Vasc Biol 21, 1196-1202.

45. Dragoni S, Gori T, Di Stolfo G, et al. (2005) Folic acid does not limit endothelial dysfunction induced by ischemia and reperfusion: a human study. J Cardiovasc Pharmacol 46, 494-497.

46. Khandanpour N, Armon MP, Jennings B, et al. (2009) Randomized clinical trial of folate supplementation in patients with peripheral arterial disease. Br J Surg 96, 990-998.

47. Lekakis JP, Papamichael CM, Papaioannou TG, et al. (2004) Oral folic acid enhances endothelial function in patients with hypercholesterolaemia receiving statins. Eur $J$ Cardiovasc Prev Rehabil 11, 416-420.

48. Mangoni AA, Sherwood RA, Swift CG, et al. (2002) Folic acid enhances endothelial function and reduces blood pressure in smokers: a randomized controlled trial. J Intern Med 252, 497-503.

49. Mangoni AA, Sherwood RA, Asonganyi B, et al. (2005) Short-term oral folic acid supplementation enhances endothelial function in patients with type 2 diabetes. Am J Hypertens 18, 220-226.

50. Olthof MR, Bosts ML, Katan MB, et al. (2006) Effect of folic acid and betaine supplementation on flow-mediated dilation: a randomized, controlled study in healthy volunteers. PLOS Clin Trials 1, e10.

51. Pena AS, Wiltshire E, Gent R, et al. (2007) Folic acid does not improve endothelial function in obese children and adolescents. Diabetes Care 30, 2122-2127.

52. Pullin CH, Ashfield-Watt PA, Burr ML, et al. (2001) Optimization of dietary folate or low-dose folic acid supplements lower homocysteine but do not enhance endothelial function in healthy adults, irrespective of the methylenetetrahydrofolate reductase (C677T) genotype. J Am Coll Cardiol 38, 1799-1805.

53. Thambyrajah J, Landray MJ, Jones HJ, et al. (2001) A randomized double-blind placebo-controlled trial of the effect of homocysteine-lowering therapy with folic acid on endothelial function in patients with coronary artery disease. J Am Coll Cardiol 37, 1858-1863.

54. Title LM, Cummings PM, Giddens K, et al. (2000) Effect of folic acid and antioxidant vitamins on endothelial dysfunction in patients with coronary artery disease. $J$ Am Coll Cardiol 36, 758-765.

55. Title LM, Ur E, Giddens K, et al. (2006) Folic acid improves endothelial dysfunction in type 2 diabetes - an effect independent of homocysteine-lowering. Vasc Med 11, 101-109.

56. Vrablik M, Stulc T, Kasalova Z, et al. (2007) Folic acid does not improve surrogate markers of early atherosclerosis in atorvastatin-treated patients. Nutr Res 27, 181-185.

57. Woodman RJ, Celermajer DE, Thompson PL, et al. (2004) Folic acid does not improve endothelial function in healthy hyperhomocysteinaemic subjects. Clin Sci (Lond) 106, 353-358.

58. Woodman RJ, Mori TA, Burke V, et al. (2003) Effects of purified eicosapentaenoic acid and docosahexaenoic acid on platelet, fibrinolytic and vascular function in hypertensive type 2 diabetic patients. Atherosclerosis 166, 85-93.

59. Armah CK, Jackson KG, Doman I, et al. (2008) Fish oil fatty acids improve postprandial vascular reactivity in healthy men. Clin Sci (Lond) 114, 679-686.

60. Dangardt F, Osika W, Chen Y, et al. (2010) Omega-3 fatty acid supplementation improves vascular function and reduces inflammation in obese adolescents. Atherosclerosis 212, 580-585.

61. Dyerberg J, Eskesen DC, Andersen PW, et al. (2004) Effects of trans- and $n-3$ unsaturated fatty acids on cardiovascular risk markers in healthy males. An 8 weeks dietary intervention study. Eur J Clin Nutr 58, 1062-1070.

62. Engler MM, Engler MB, Malloy M, et al. (2004) Docosahexaenoic acid restores endothelial function in children with hyperlipidemia: results from the EARLY study. Int $J$ Clin Pharmacol Ther 42, 672-679.

63. Fahs CA, Yan H, Ranadive S, et al. (2010) The effect of acute fish-oil supplementation on endothelial function and arterial stiffness following a high-fat meal. Appl Physiol Nutr Metab 35, 294-302.

64. Goodfellow J, Bellamy MF, Ramsey MW, et al. (2000) Dietary supplementation with marine omega- 3 fatty acids improve systemic large artery endothelial function in subjects with hypercholesterolemia. J Am Coll Cardiol 35 $265-270$.

65. Hill AM, Buckley JD, Murphy KJ, et al. (2007) Combining fish-oil supplements with regular aerobic exercise improves body composition and cardiovascular disease risk factors. Am J Clin Nutr 85, 1267-1274.

66. Khan F, Elherik K, Bolton-Smith C, et al. (2003) The effects of dietary fatty acid supplementation on endothelial function and vascular tone in healthy subjects. Cardiovasc Res 59, 955-962. 
67. Mita T, Watada H, Ogihara T, et al. (2007) Eicosapentaenoic acid reduces the progression of carotid intima-media thickness in patients with type 2 diabetes. Atherosclerosis 191, $162-167$.

68. Morgan DR, Dixon LJ, Hanratty CG, et al. (2006) Effects of dietary omega-3 fatty acid supplementation on endothelium-dependent vasodilation in patients with chronic heart failure. Am J Cardiol 97, 547-551.

69. Rizza S, Tesauro M, Cardillo C, et al. (2009) Fish oil supplementation improves endothelial function in normoglycemic offspring of patients with type 2 diabetes. Atherosclerosis 206, 569-574.

70. Sanders TAB, Gleason K, Griffin B, et al. (2006) Influence of an algal triacylglycerol containing docosahexaenoic acid (22:6n-3) and docosapentaenoic acid (22:5n-6) on cardiovascular risk factors in healthy men and women. $\mathrm{Br} J$ Nutr 95, 525-531.

71. Satoh N, Shimatsu A, Kotani K, et al. (2009) Highly purified eicosapentaenoic acid reduces cardio-ankle vascular index in association with decreased serum amyloid A-LDL in metabolic syndrome. Hypertens Res 32, 1004-1008.

72. Schiano V, Laurenzano E, Brevetti G, et al. (2008) Omega-3 polyunsaturated fatty acid in peripheral arterial disease: effect on lipid pattern, disease severity, inflammation profile, and endothelial function. Clin Nutr 27, 241-247.

73. Shah AP, Ichiuji AM, Han JK, et al. (2007) Cardiovascular and endothelial effects of fish oil supplementation in healthy volunteers. J Cardiovasc Pharmacol Ther 12, 213-219.

74. Skulas-Ray AC, Kris-Etherton PM, Harris WS, et al. (2011) Dose-response effects of omega- 3 fatty acids on triglycerides, inflammation, and endothelial function in healthy persons with moderate hypertriglyceridemia. $A m \mathrm{~J}$ Clin Nutr 93, 243-252.

75. Stirban A, Nandrean S, Gotting C, et al. (2010) Effects of $n-3$ fatty acids on macro- and microvascular function in subjects with type 2 diabetes mellitus. Am J Clin Nutr 91, 808-813.

76. Theobald HE, Goodall AH, Sattar N, et al. (2007) Low-dose docosahexaenoic acid lowers diastolic blood pressure in middle-aged men and women. J Nutr 137, 973-978.

77. Wong CY, Yiu KH, Li SW, et al. (2010) Fish-oil supplement has neutral effects on vascular and metabolic function but improves renal function in patients with type 2 diabetes mellitus. Diabet Med 27, 54-60.

78. Balzer J, Rassaf T, Heiss C, et al. (2008) Sustained benefits in vascular function through flavanol-containing cocoa in medicated diabetic patients a double-masked, randomized, controlled trial. J Am Coll Cardiol 51, 2141-2149.

79. Berry NM, Davison K, Coates AM, et al. (2010) Impact of cocoa flavanol consumption on blood pressure responsiveness to exercise. Br J Nutr 103, 1480-1484.

80. Davison K, Coates AM, Buckley JD, et al. (2008) Effect of cocoa flavanols and exercise on cardiometabolic risk factors in overweight and obese subjects. Int $J$ Obes (Lond) 32, 1289-1296.

81. Engler MB, Engler MM, Chen CY, et al. (2004) Flavonoidrich dark chocolate improves endothelial function and increases plasma epicatechin concentrations in healthy adults. J Am Coll Nutr 23, 197-204.

82. Faridi Z, Njike VY, Dutta S, et al. (2008) Acute dark chocolate and cocoa ingestion and endothelial function: a randomized controlled crossover trial. Am J Clin Nutr $\mathbf{8 8}$, $58-63$.

83. Farouque HM, Leung M, Hope SA, et al. (2006) Acute and chronic effects of flavanol-rich cocoa on vascular function in subjects with coronary artery disease: a randomized double-blind placebo-controlled study. Clin Sci (Lond) 111, $71-80$.

84. Grassi D, Desideri G, Necozione S, et al. (2008) Blood pressure is reduced and insulin sensitivity increased in glucose-intolerant, hypertensive subjects after 15 days of consuming high-polyphenol dark chocolate. J Nutr 138, $1671-1676$.

85. Grassi D, Necozione S, Lippi C, et al. (2005) Cocoa reduces blood pressure and insulin resistance and improves endothelium-dependent vasodilation in hypertensives. Hypertension 46, 398-405.

86. Heiss C, Kleinbongard P, Dejam A, et al. (2005) Acute consumption of flavanol-rich cocoa and the reversal of endothelial dysfunction in smokers. J Am Coll Cardiol 46, $1276-1283$.

87. Heiss C, Jahn S, Taylor M, et al. (2010) Improvement of endothelial function with dietary flavanols is associated with mobilization of circulating angiogenic cells in patients with coronary artery disease. J Am Coll Cardiol 56, 218-224.

88. Muniyappa R, Hall G, Kolodziej TL, et al. (2008) Cocoa consumption for 2 wk enhances insulin-mediated vasodilatation without improving blood pressure or insulin resistance in essential hypertension. Am J Clin Nutr 88, $1685-1696$.

89. Njike VY, Fairdi Z, Shuval K, et al. (2011) Effects of sugarsweetened and sugar-free cocoa on endothelial function in overweight adults. Int J Cardiol 149, 83-88.

90. Schroeter H, Heiss C, Balzer J, et al. (2006) (-)-Epicatechin mediates beneficial effects of flavanol-rich cocoa on vascular function in humans. Proc Natl Acad Sci U S A 103, 1024-1029.

91. Vlachopoulos C, Aznaouridis $\mathrm{K}$, Alexopoulos $\mathrm{N}$, et al. (2005) Effect of dark chocolate on arterial function in healthy individuals. Am J Hypertens 18, 785-791.

92. Wang-Polagruto JF, Villablanca AC, Polagruto JA, et al. (2006) Chronic consumption of flavanol-rich cocoa improves endothelial function and decreases vascular cell adhesion molecule in hypercholesterolemic postmenopausal women. J Cardiovasc Pharmacol 47, Suppl. 2, S177-S186 (discussion S206-S209).

93. Chan YH, Lau KK, Yiu KH, et al. (2008) Reduction of C-reactive protein with isoflavone supplement reverses endothelial dysfunction in patients with ischaemic stroke. Eur Heart J 29, 2800-2807.

94. Clerici C, Setchell KDR, Battezzati PM, et al. (2007) Pasta naturally enriched with isoflavone aglycons from soy germ reduces serum lipids and improves markers of cardiovascular risk. J Nutr 137, 2270-2278.

95. Clerici C, Nardi E, Battezzati PM, et al. (2011) Novel soy germ pasta improves endothelial function, blood pressure, and oxidative stress in patients with type 2 diabetes. Diabetes Care 34, 1946-1948.

96. Colacurci N, Chiantera A, Fornaro F, et al. (2005) Effects of soy isoflavones on endothelial function in healthy postmenopausal women. Menopause 12, 299-307.

97. Cuevas AM, Irribarra VL, Castillo OA, et al. (2003) Isolated soy protein improves endothelial function in postmenopausal hypercholesterolemic women. Eur J Clin Nutr 57, 889-894.

98. Evans M, Njike VY, Hoxley M, et al. (2007) Effect of soy isoflavone protein and soy lecithin on endothelial function in healthy postmenopausal women. Menopause 14, 141-149.

99. Hale G, Paul-Labrador M, Dwyer JH, et al. (2002) Isoflavone supplementation and endothelial function in menopausal women. Clin Endocrinol (Oxf) 56, 693-701. 
100. Hall WL, Formanuik NL, Harnpanich D, et al. (2008) A meal enriched with soy isoflavones increases nitric oxidemediated vasodilation in healthy postmenopausal women. J Nutr 138, 1288-1292.

101. Hallund J, Bugel S, Tholstrup T, et al. (2006) Soya isoflavone-enriched cereal bars affect markers of endothelial function in postmenopausal women. Br J Nutr 95, 1120-1126.

102. Hermansen K, Hansen B, Jacobsen R, et al. (2005) Effects of soy supplementation on blood lipids and arterial function in hypercholesterolaemic subjects. Eur J Clin Nutr 59, 843-850.

103. Katz DL, Evans MA, Njike VY, et al. (2007) Raloxifene, soy phytoestrogens and endothelial function in postmenopausal women. Climacteric 10, 500-507.

104. Kreijkamp-Kaspers S, Kok L, Bots ML, et al. (2005) Randomized controlled trial of the effects of soy protein containing isoflavones on vascular function in postmenopausal women. Am J Clin Nutr 81, 189-195.

105. Lissin LW, Oka R, Lakshmi S, et al. (2004) Isoflavones improve vascular reactivity in post-menopausal women with hypercholesterolemia. Vasc Med 9, 26-30.

106. Nestel P, Fujii A \& Zhang L (2007) An isoflavone metabolite reduces arterial stiffness and blood pressure in overweight men and postmenopausal women. Atherosclerosis 192, 184-189.

107. Simons LA, von Konigsmark M, Simons J, et al. (2000) Phytoestrogens do not influence lipoprotein levels or endothelial function in healthy, postmenopausal women. Am J Cardiol 85, 1297-1301.

108. Squadrito F, Altavilla D, Morabito N, et al. (2002) The effect of the phytoestrogen genistein on plasma nitric oxide concentrations, endothelin-1 levels and endothelium dependent vasodilation in postmenopausal women. Atherosclerosis 163, 339-347.

109. Squadrito F, Altavilla D, Crisafulli A, et al. (2003) Effect of genistein on endothelial function in postmenopausal women: a randomized, double-blind, controlled study. Am J Med 114, 470-476.

110. Teede HJ, Dalais FS, Kotsopoulos D, et al. (2001) Dietary soy has both beneficial and potentially adverse cardiovascular effects: a placebo-controlled study in men and postmenopausal women. J Clin Endocrinol Metab 86, 3053-3060.

111. Teede HJ, Giannopoulos D, Dalais FS, et al. (2006) Randomised, controlled, cross-over trial of soy protein with isoflavones on blood pressure and arterial function in hypertensive subjects. J Am Coll Nutr 25, 533-540.

112. Villa P, Costantini B, Suriano R, et al. (2009) The differential effect of the phytoestrogen genistein on cardiovascular risk factors in postmenopausal women: relationship with the metabolic status. J Clin Endocrinol Metab 94, 552-558.

113. US National Library of Medicine (NLM) (2012) Abridged Index Medicus (AIM or "Core Clinical") journal titles. http://www.nlm.nih.gov/bsd/aim.html (accessed 4 September 2013)

114. Hooper L, Kay C, Abdelhamid A, et al. (2012) Effects of chocolate, cocoa, and flavan-3-ols on cardiovascular health: a systematic review and meta-analysis of randomized trials. Am J Clin Nutr 95, 740-751.

115. Shrime MG, Bauer SR, McDonald AC, et al. (2011) Flavonoid-rich cocoa consumption affects multiple cardiovascular risk factors in a meta-analysis of short-term studies. J Nutr 141, 1982-1988.
116. Pase MP, Grima NA \& Sarris J (2011) Do long-chain $n$-3 fatty acids reduce arterial stiffness? A meta-analysis of randomised controlled trials. Br J Nutr 106, 974-980.

117. Wang Q, Liang X, Wang L, et al. (2012) Effect of omega-3 fatty acids supplementation on endothelial function: a meta-analysis of randomized controlled trials. Atherosclerosis 221, 536-543.

118. Beavers DP, Beavers KM, Miller M, et al. (2012) Exposure to isoflavone-containing soy products and endothelial function: a Bayesian meta-analysis of randomized controlled trials. Nutr Metab Cardiovasc Dis 22, 182-191.

119. McRae MP (2009) High-dose folic acid supplementation effects on endothelial function and blood pressure in hypertensive patients: a meta-analysis of randomized controlled clinical trials. J Chiropr Med 8, 15-24.

120. de Bree A, van Mierlo LA \& Draijer R (2007) Folic acid improves vascular reactivity in humans: a meta-analysis of randomized controlled trials. Am J Clin Nutr 86, 610-617.

121. Balk EM, Bonis PAI, Moskowitz H, et al. (2002) Correlation of quality measures with estimates of treatment effect in meta-analyses of randomized controlled trials. JAMA 287, 2973-2982.

122. Moher D, Pham B, Jones A, et al. (1998) Does quality of reports of randomised trials affect estimates of intervention efficacy reported in meta-analyses? Lancet 352, 609-613.

123. Klein MA, Nahin RL, Messina MJ, et al. (2010) Guidance from an NIH workshop on designing, implementing, and reporting clinical studies of soy interventions. J Nutr 140, 1192S-1204S.

124. Anderson TJ, Uehata A, Gerhard ME, et al. (1995) Close relation of endothelial function in the human coronary and peripheral circulations. J Am Coll Cardiol 26, 1235-1241.

125. Gokce N, Keaney JF Jr, Hunter LM, et al. (2003) Predictive value of noninvasively determined endothelial dysfunction for long-term cardiovascular events in patients with peripheral vascular disease. J Am Coll Cardiol 41, 1769-1775.

126. Gokee N, Keaney JF Jr, Hunter LM, et al. (2002) Risk stratification for postoperative cardiovascular events via noninvasive assessment of endothelial function: a prospective study. Circulation 105, 1567-1572.

127. Brevetti G, Silvestro A, Schiano V, et al. (2003) Endothelial dysfunction and cardiovascular risk prediction in peripheral arterial disease: additive value of flow-mediated dilation to ankle-brachial pressure index. Circulation 108, 2093-2098.

128. Fathi R, Haluska B, Isbel NM, et al. (2004) The relative importance of vascular structure and function in predicting cardiovascular events. J Am Coll Cardiol 43, 616-623.

129. Frick M, Suessenbacher A, Alber HF, et al. (2005) Prognostic value of brachial artery endothelial function and wall thickness. J Am Coll Cardiol 46, 1006-1010.

130. Deanfield J, Donald A, Ferri C, et al. (2005) Endothelial function and dysfunction. Part I: Methodological issues for assessment in the different vascular beds: a statement by the Working Group on Endothelin and Endothelial Factors of the European Society of Hypertension. $J$ Hypertens 23, 7-17.

131. Thijssen DHJ, Black MA, Pyke KE, et al. (2011) Assessment of flow-mediated dilation in humans: a methodological and physiological guideline. Am J Physiol Heart Circ Physiol 300, $\mathrm{H} 2-\mathrm{H} 12$.

132. Welsch MA, Allen JD \& Geaghan JP (2002) Stability and reproducibility of brachial artery flow-mediated dilation. Med Sci Sports Exerc 34, 960-965. 